\title{
What if plant functional types conceal species-specific responses to environment? Study on arctic shrub communities
}

\author{
Patrick SACCone, ${ }^{1,5}$ Kristinna Hoikka, ${ }^{2}$ and Risto VirTANEN ${ }^{1,3,4}$ \\ ${ }^{1}$ Department of Ecology and Genetics, University of Oulu, P. O. Box 3000, FI-90014 Oulu, Finland \\ ${ }^{2}$ Metsähallitus, Koskikatu 44, 96100 Rovaniemi, Finland \\ ${ }^{3}$ Department of Physiological Diversity, Helmholtz Center for Environmental Research - UFZ, \\ Permoserstrasse 15, 04318 Leipzig, Germany \\ ${ }^{4}$ German Center for Integrative Biodiversity Research (iDiv), Deutscher Platz 5a, 04103 Leipzig, Germany
}

\begin{abstract}
Plant functional types (PFT) are increasingly used to outline biome-scale plantenvironment relationship and predict global change effects on community structure. However, the potentials and limitations of the PFT approach have to be tested as they can be less sensitive than trait-based or species-level approaches. Here, we compare the responses of deciduous-evergreen shrub PFTs and species to gradual snow-related environmental conditions by also considering effects of aboveground architectural traits and neighboring shrubs. Five deciduous species and four evergreen dwarf shrub species were transplanted to be exposed to four levels of winter snow cover across mesotopographic gradients in northern Fennoscandian tundra. The survival and growth of individually tagged shoots were monitored over one year, and the change in cover of shrubs was monitored over four years. Evergreen species showed higher resistance to environmental severity and generally benefitted from higher abundance of neighboring shrubs. Deciduous species exhibited negligible to drastic responses to snow thickness and neighboring shrubs tended to have a negative effect on their performance and survival. Tall shoots of deciduous shrubs survived poorly under the thinnest snow cover. Overall, deciduous and evergreen PFTs showed modest differences in their performances along the gradient. Our results show that deciduous-evergreen leaf phenology categories predict shrub responses to changing environmental conditions only to a limited extent. Our findings highlight strong species-specific responses especially among deciduous shrubs, and a differential role of plant-plant interactions for shrubs. Our results emphasize that distribution patterns of arctic-alpine shrubs and shrub community responses to altered snow regimes depend on species-level plant functional attributes, species interactions and species-specific sensitivities to environmental severity.
\end{abstract}

Key words: arctic-alpine tundra; mesotopographic gradient; plant functional types; plant interactions; snow cover; transplant experiment.

\section{INTRODUCTION}

Plant functional type (PFT) approach has been developed in order to reveal general rules relating vegetation to environmental conditions (Lavorel et al. 2007, Díaz et al. 2016). The PFT concept, rooted in early strategies' classification by von Humboldt (1806), has been largely used and improved addressing a range of questions in empirical and theoretical ecology and drawing some general principles. For instance, large-scale studies successfully associated leaf economics' traits or resourceuse strategies with environmental constraints across flora and phylogenetic groups (see Díaz and Cabido 1997, Diaz et al. 2004, Grubb 2016). PFT-based analyses have identified broad-scale patterns in relation to climate and anthropogenic drivers (Engemann et al. 2016) and revealed broad consistencies in competition effects

Manuscript received 18 August 2016; revised 2 February 2017; accepted 6 March 2017. Corresponding Editor: Joseph B. Yavitt.

${ }^{5}$ E-mail: patrick.saccone@gmail.com on tree communities (Kunstler et al. 2016). The PFT approach also enabled including vegetation heterogeneity into Dynamic Vegetation Models (DVMs). Then, they enabled implementing Earth System Models with a more realistic biotic component for the predictive effort of ecosystem response to environmental changes (Epstein et al. 2001, Wullschleger et al. 2014).

Despite their remarkable potential, the PFT approach is limited by some features. First, the PFT concept assumes a tight linkage between plant occurrence and environmental conditions (Grime 1977, Epstein et al. 2001) while community-structuring processes buffer such direct correlation. For instance, plant-plant interactions are well-known modulators of plant distribution along environmental gradients restricting their realized niche through competition (Silvertown 2004) or reversely expanding the range of suitable habitats through facilitation (Bruno et al. 2003). Second, pooling species into PFT might conceal essential inter- (Dormann and Woodin 2002) and intraspecific (Albert et al. 2010) variability leading to no identifiable patterns of PFT distribution along environmental gradients. Despite successful global 
analyses, the extent to which PFTs predict plant responses to changing environment is still inadequately understood. As partial solutions, instead of using plant types, quantitative tissue trait and architecture-based analyses have been advocated (Westoby and Wright 2006, Shipley 2010, Higgins et al. 2016). Moreover, a better integration of community ecology concepts and local-scale processes has been identified as a crucial requirement for the improvement of plant distribution modeling (Guisan and Thuiller 2005, Scheiter et al. 2013, Mod et al. 2015).

The split between deciduous and evergreen plant types is one of the broad general features in evolution and ecology (Chabot and Hicks 1982, Givnish 2002) and it is a key leaf attribute in PFT schemes (Kattge et al. 2011). The distribution of deciduous and evergreen leaf types is found to be linked to global climate regimes (Wright et al. 2005, Buitenwerf and Higgins 2016): the deciduous types are favored in environments with strong seasonal variation in growth-limiting factors and shedding leaves during unfavorable seasons improves long-term plant net carbon gain (Kikuzawa 1991, Givnish 2002, Manzoni et al. 2015). Chapin et al. (1996) found that, even in a system as poorly diverse as the arctic tundra, splitting shrubs into deciduous and evergreen groups is ecologically motivated. They linked shrub evergreenness to dry and infertile conditions while deciduous species were favored by moist and nutrient-rich conditions. On the other hand, Oksanen and Virtanen (1995) described in northern Fennoscandia the prevalence of evergreen dwarf shrubs under thick snowpack while deciduous ones dominated under thin snow cover and cold winters. A broader-scale biogeographic data from arctic-oroarctic gradients (Virtanen et al. 1999) and Givnish's (2002) review have also supported the idea that the deciduous habit should be favored under snow-free to thin snow cover conditions as opposed to evergreens suffering from winter desiccation and associated long-term lethal injuries.

In cold systems, the amplitude of environmental conditions along mesotopography is, in large part, linked to snow blown off of ridges that gradually accumulates toward the bottom of the snowbed (Walker et al. 2001). Thick snow cover over the winter in the snowbed directly protects vegetation from wind abrasion and desiccation risk experienced under thin and nearly absent snowpack (Warren Wilson 1959). On the other hand, delayed snowmelt of accumulated snowpack shortens the growing season while deep snowpack can injure plants and lengthen the dark respiration period (Sonesson and Callaghan 1991). Most importantly, a myriad of winter and spring snow-related processes make a complex mesotopographical environmental gradient in tundra systems (Billings 1973, Stanton et al. 1994). Wind may blow off litter from ridges while thin or non-permanent winter snowpack may reduce litter decomposition, both mechanisms limiting the formation of proper soil (Sonesson and Callaghan 1991, Saccone et al. 2013). Desiccation by wind and snowmelt often maintain a soil moisture gradient (Billings 1973), while leachate, trapping of aeolian material (organic and mineral material blown off by wind in the surrounding area) in the snowbed, or runoff can add a delay in biogeochemical cycles accentuating soil resource gradients (Giblin et al. 1991, Walker et al. 2001, but see Stanton et al. 1994).

Winter snow condition is increasingly recognized as a major parameter of arctic vegetation structure (Walker et al. 2001, Wahren et al. 2005, Wheeler et al. 2016). Although several studies investigated the effect of altered snow regime on tundra structure and function (see, for instance, Wahren et al. 2005, Bokhorst et al. 2009, Preece et al. 2012, Vankoughnett and Grogan 2016), the sensitivity of tundra shrubs to gradual levels of snow conditions has been experimentally tested on a very limited basis. The distribution of species and plant communities along mesotopographic gradients has been documented world-wide in tundra regions (see Vestergren 1902, Braun-Blanquet 1923, Dahl 1957, Stanton et al. 1994, Walker et al. 2001). These documentations identify chionophobous and chionophilous species and their distributions are thought to reflect species-specific adaptation and community-level processes (Wijk 1986, Stanton et al. 1994, Heegaard 2002, Heegaard and Vandvik 2004, Odland and Munkejord 2008). Whether any functional type convergence prevails along mesotopographic gradients is less well understood. Are communities on exposed ridges or those that are snow-sheltered characterized by similar functional types, and is such convergence captured by current PFT schemes? The extent to which intermediate levels of snow cover affect tundra communities and how these outcomes depend on plant-plant interactions are even less well known. Both positive and negative interactions can modulate plant responses to environmental conditions and then modify their distribution along the mesotopography. Moreover, these interactions are also prone to shift along environmental gradients (see the stress gradient hypothesis [SGH], Carlsson and Callaghan 1991, Bertness and Callaway 1994, Brooker and Callaghan 1998) adding complexity to the predictability of plant distribution.

In this study, we experimentally explored the potentials and limitations of the PFT approach to capture shrub distributions along a mesotopographic snow-related gradient in the north Fennoscandian mountain tundra. We monitored the survival and growth performance of five deciduous and four evergreen dwarf shrubs transplanted at four levels along the gradient from ridge to snowbed. We hypothesized (1) that the relevance of the PFT scheme regarding snow regimes would be evidenced by different survival and growth performance patterns between evergreens and deciduous along the snow cover gradient and that (2) this difference between PFTs would be greater than the differences in growth and survival among species. We expected (3) an experimental confirmation that a leaf-shedding strategy would prevent deciduous shrubs from winter damage and favor their survival under exposed conditions. We also explored (4) the potential of aboveground architectural traits as predictors of mountain tundra shrub performances and (5) tested to what 
extent neighboring shrubs modulate these patterns among the different levels of snow protection.

\section{Materials And Methods}

\section{Study site and experimental design}

The study was conducted at Kilpisjärvi in the Northwestern Finnish Lapland $\left(69^{\circ} 01^{\prime} \mathrm{N}\right.$ and $\left.20^{\circ} 50^{\prime} \mathrm{E}\right)$. The experiment was established on the SW lower slope of Mt. Jehkats at $600 \mathrm{~m}$ above sea level, above the timberline formed by mountain birch (Betula pubescens ssp. czerepanovii). The habitat is a mountain tundra heath and the vegetation is characterized by low $B$. nana scrub, dwarf shrubs, mosses, and lichens. The experimental design included four replicated mesotopographic gradients from a windswept area toward a depression with gradually deepening snow cover. On each gradient, within a distance of about $10 \mathrm{~m}$, four levels of snow cover (so called topography treatment) were visually identified from previous winter and spring visits: blown-off (nearly absent), thin $(\sim 30 \mathrm{~cm})$, moderate $(\sim 80 \mathrm{~cm})$, and deep $(>80 \mathrm{~cm})$ snow cover. The vegetation diverged among the four levels of snow cover and, except on the wind-swept areas, formed a continuous layer as well as remained under the snowpack during the winter. On the windswept areas the vascular vegetation was composed mainly of Arctostaphylos alpina, Loiseleuria procumbens, and Empetrum nigrum ssp. hermaphroditum (henceforth E. nigrum for brevity). On the area of thin snow cover, the vegetation was composed mostly of E. nigrum. On the area of moderate snow cover, B. nana was the most abundant dwarf shrub. On the areas of the deepest snow cover, Vaccinium myrtillus was abundant and also some Salix herbacea occurred.

Nine common dwarf shrub species representing some range of leaf and stature strategies from this nutrientdeficient heath habitat were targeted in this study. The evergreens included E. nigrum, L. procumbens, Phyllodoce caerulea, and $V$. vitis-idaea, and deciduous shrubs were A. alpina, B. nana, S. herbacea, V. myrtillus, and V. uliginosum. In early June 1998, after the soil thaw, $40 \times 40 \mathrm{~cm}$ sod blocks including soil $(\sim 10 \mathrm{~cm}$, corresponding to the main rooting zone) and vegetation, where (at least) one target species was abundant enough to randomly select one individual, were dug up from the gradients' surrounding area where vegetation was continuous. Blocks were cut to insure a sufficient buffer zone around target individuals and limit transplantation impacts. Two blocks per target species were then transplanted at each topographic level along each of the four gradients. The complete design consisted of 231 blocks for 288 experimental units (4 gradients $\times 4$ topographic levels $\times$ 9 species $\times 2$ blocks) because some of the blocks were used for more than one species (considering that the two individuals of the same species were always selected in different blocks). In early August 1998, at the end of the growing period, the overall condition of the targets was checked to assess the effect of the transplantation procedure on shrub ramets. Almost none of the transplants showed signs of dieback. Then, three shoots per selected individual in good condition were randomly selected and tagged by a plastic pin and their heights (centimeters above ground level) were recorded. The percentage cover of the nine target species was estimated from a $20 \times 20 \mathrm{~cm}$ quadrat in the central area of each block.

In August 1999, the number of dead and living branches per tagged shoot was counted and the apical and lateral growth of tagged shoots was measured. In 2002, the cover of the nine target species was re-estimated using the same protocol as in 1998.

\section{Data compilation and statistical analysis}

The experiment was designed to primarily test the performance responses of contrasting target species to environmental exposure and question functional type segregation among tundra dwarf shrubs. We also sought to explore the potential for relationships between these performance responses (at the PFT and specific levels) and initial aboveground architectural species traits or neighboring shrub community structure. Therefore, the responses were quantified by survival and growth performances. Survival was estimated at the shoot level considered dead when no living branches were identified in 1999. Since shoots grew either apically or laterally, both values were measured after one year of the experiment and pooled in a single growth metric ( $\mathrm{mm}$ ) at the shoot level. We also used the change in cover at the sod-block level over the four years of the experiment as a longerterm indicator of species growth and survival performances. The initial height of tagged shoots was averaged at the individual level and joined the individual cover as target species traits. To expand the test for potential relationships, we calculated a proxy of target individual volume (in $\mathrm{cm}^{3}$ ) as the cover (percentage of $400 \mathrm{~cm}^{2}$ ) multiplied by average shoot height $(\mathrm{cm})$. The cover of the nine target species was pooled to estimate the total shrub community cover (no other shrub species occurred in the transplants). Then, the neighboring shrub cover was calculated at the sod-block level as the sum of the nine shrubs' abundance excluding the target species. As for target individuals, the volume proxy of the neighboring shrubs was calculated at the sod-block level: for each shrub species within the sod-block, the cover was multiplied by the average initial height among the 32 individuals from the entire design. The abundance of neighboring shrubs was, therefore, considered in terms of cover and volume metrics and for the initial (1998) and final (2002) stages of the experiment. Survival and growth performances after one year of the experiment were analyzed at the shoot level, while the change in cover after four years was analyzed at the sod-block level, as well as the relationships between performances and traits of the target species or the abundance of neighboring shrubs.

The responses of target species to environmental exposure were analyzed using Generalized Linear Models 
TABLE 1. Effects of plant functional type (PFT), topography and their interaction on target individual (a) survival and (b) growth after one year of the experiment, and (c) on target species change in cover after four years of the experiment pooled at the PFT level.

\begin{tabular}{|c|c|c|c|c|c|c|c|c|c|}
\hline \multirow[b]{2}{*}{ Source of deviation } & \multicolumn{3}{|c|}{ (a) Survival after 1 year } & \multicolumn{3}{|c|}{ (b) Growth after 1 year } & \multicolumn{3}{|c|}{$\begin{array}{c}\text { (c) Cover change after } \\
4 \text { years }\end{array}$} \\
\hline & df & $F$ & $P$ & df & $F$ & $P$ & df & $F$ & $P$ \\
\hline PFT & 1 & 1.35 & 0.2453 & 1 & 1.85 & 0.1742 & 1 & 0 & 0.9563 \\
\hline Topography & 3 & 18.22 & $<0.0001$ & 3 & 5.25 & 0.0014 & 3 & 4.25 & 0.0059 \\
\hline PFT $\times$ Topography & 3 & 4.06 & 0.007 & 3 & 0.83 & 0.4789 & 3 & 1.21 & 0.3077 \\
\hline Residuals & 856 & & & 664 & & & 272 & & \\
\hline
\end{tabular}

Notes: The effects were tested by generalized linear models. Boldface type indicates significant effects $(P<0.05)$ of the explanatory variables.

(glm function in the stats package; R Development Core Team 2013), and the significances of explanatory variables were assessed using the Anova function in the car package (Fox and Weisberg 2011). Alongside topography (four levels of environmental exposure), plant functional type and species identity within each PFT were used as explanatory variables to test singular effects and their interactions on target individual survival and growth after one year of the experiment and change in cover of target species after four years of the experiment. The survivorship of individual shoots represented a binary response variable (dead or alive) and hence logistic regression (quasibinomial error structure and logit link function) was used. The growth measures and change in cover values were square-root and arcsine transformed, respectively, to meet statistical assumptions and linear regression (Gaussian error structure and identity link function) was used.

The overall effects of initial target traits and of the initial and final abundance of neighboring shrubs on the performance of target species and their interactions with environmental exposure were similarly analyzed using GLM. Moreover, direct correlations between the performance of target species and traits of the target species or the abundance of neighboring shrubs at the sod-block level were analyzed using linear models ( $1 \mathrm{~m}$ function in the stats package; R Development Core Team 2013) for the whole design and within each of the four topography levels. The analysis of topography effect on each species-specific response performance included post hoc tests using the HSD.test function in the agricolae package (de Mendiburu 2014) in R.

\section{RESULTS}

\section{Shrub responses to environmental gradient}

Mesotopography turned out to be the main factor affecting the survival and growth performances of both functional types (topography effect, Table 1). Both deciduous and evergreen shrubs showed consistent decreasing shoot survival and growth rates from the snowbeds to the ridges (Fig. 1a, b) matching with the presumption of the increasing environmental harshness toward winter-time exposed conditions. Along the same line, the cover of both deciduous and evergreen PFTs was stable under the deep snow and significantly decreased on the exposed ridges over the four years of the experiment (Fig. 1c). Although both deciduous and evergreen PFTs showed similar overall patterns, a significant PFT-topography interaction (Table 1) highlights a higher survival of evergreen shrubs than deciduous ones in the exposed end of the mesotopographic gradient (thin snowpack $F_{1,214}=13.46, P<0.0001$; blown-off

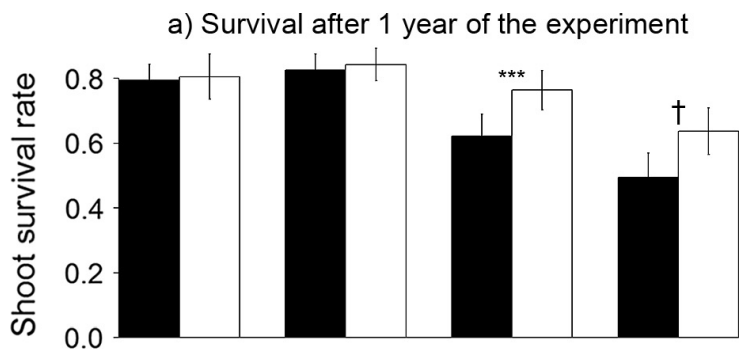

b) Growth after 1 year of the experiment

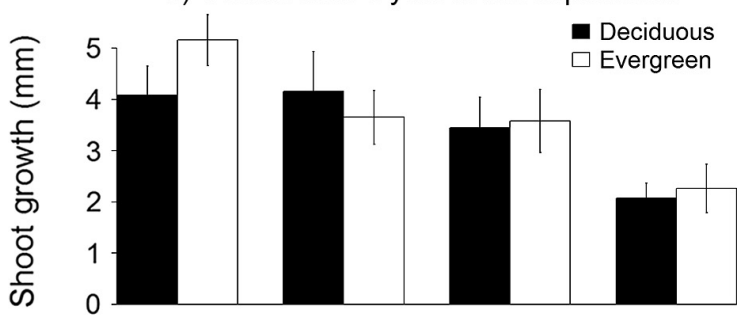

c) Cover change after 4 years of the experiment

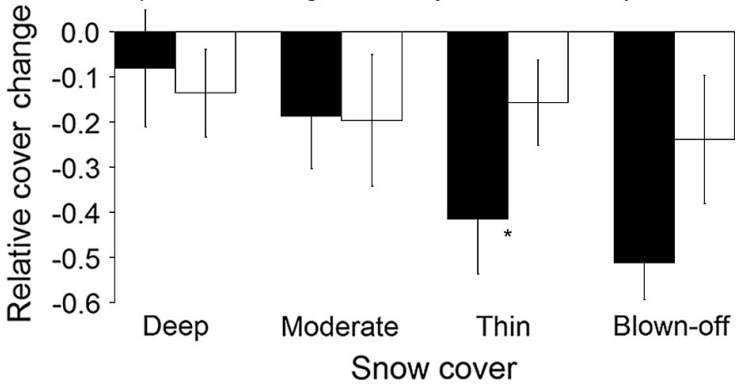

FIG. 1. Shoot (a) survival and (b) growth performances of the target individuals after one year of the experiment and (c) relative change in cover of the target species after four years of the experiment (mean $\pm \mathrm{SE}$ ) pooled at the plant functional type (PFT) level at each topography level. Asterisks above the bar groups indicate significant effects of the PFT on performance. $* * * P<0.001 ; * P<0.05 ; \dagger P<0.1$. 
snowpack $F_{1,214}=2.89, P<0.1$; Fig. 1a). The relative changes in cover of deciduous and evergreen PFTs did not significantly differ under the deeper snow cover, but the cover of deciduous species decreased significantly more under thin snowpack $\left(F_{1,69}=5.60, P<0.05\right)$ and same trend appeared on the ridges (Fig. 1c).

Within each PFT, species' shoot survival and growth rates showed specific responses to the environmental

a) Survival after 1 year of the experiment

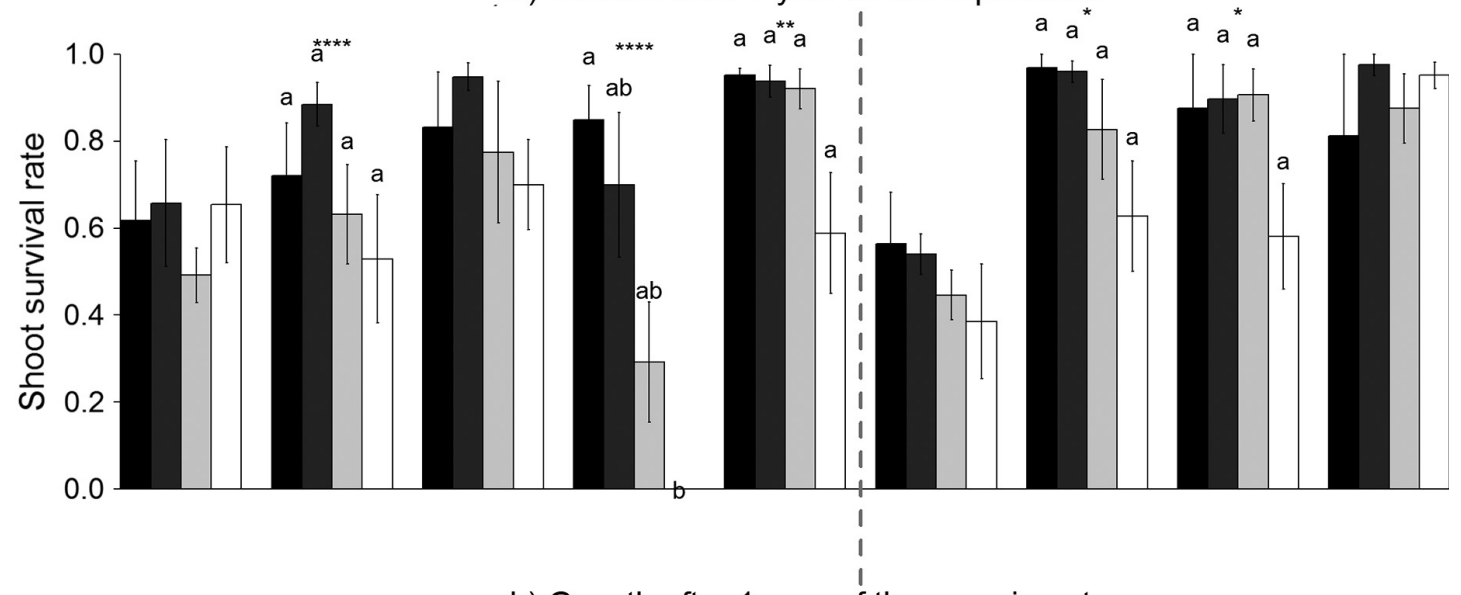

b) Growth after 1 year of the experiment

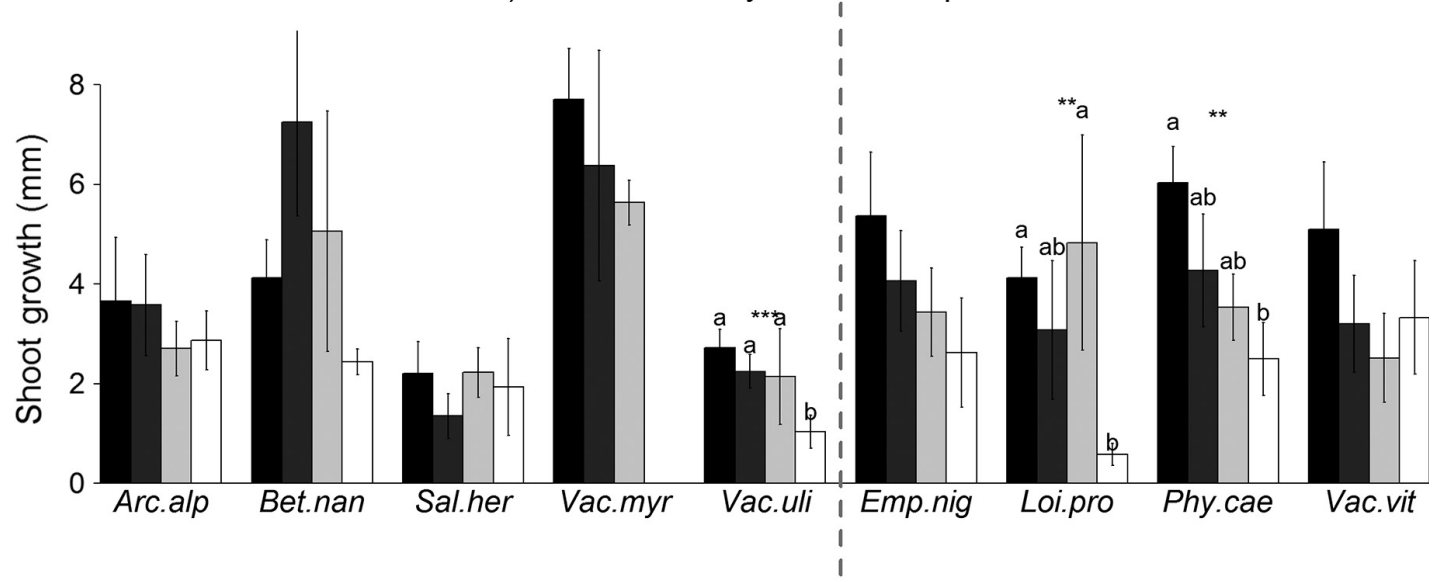

c) Cover change after 4 years of the experiment

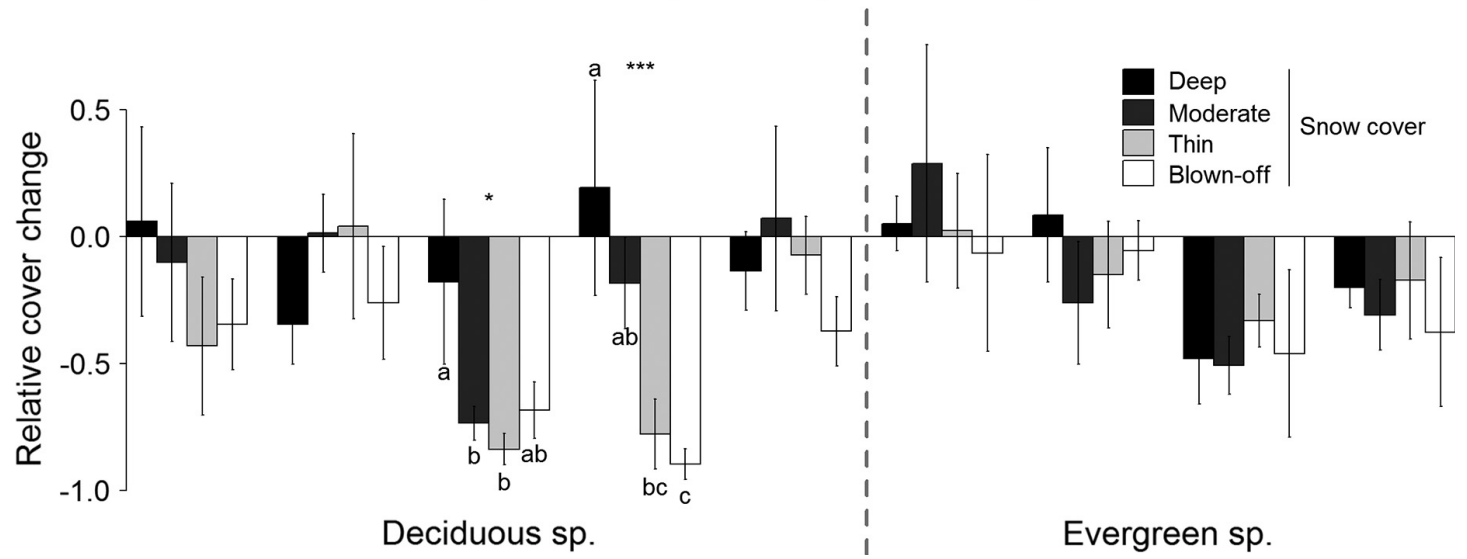

FIG. 2. Specific shoot (a) survival and (b) growth performances of the target individuals after one year of the experiment and (c) relative change in cover of the target species after four years of the experiment (mean $\pm \mathrm{SE}$ ). Asterisks above the bar groups indicate significant effects of the topography on the performance $(* * * * P<0.0001 ; * * * P<0.001 ; * P<0.05)$ and different letters indicate significantly different groups based on post hoc tests $(P<0.05)$. Species names are detailled in the experimental design section of the Materials and methods. 
mesotopographic gradient (Fig. 2a, b). The weak but consistent negative response to environmental constraints among evergreen species was significantly highlighted for L. procumbens and P. caerulea (Fig. 2a for survival, $L$. procumbens $F_{3,92}=3.19, \quad P<0.05$ and $P$. caerulea $F_{3,92}=3.29, P<0.05$; Fig $2 \mathrm{~b}$ for growth, $L$. procumbens $F_{3,71}=4.20, \quad P<0.01$ and $P$. caerulea $F_{3,70}=4.09$, $P<0.01)$. More interestingly, significant species-topography interactions (Table 2) revealed strong and contrasted responses among deciduous species. A. alpina exhibited relatively low survival rates but also a high tolerance to changing environmental conditions (no topography effect on both survival $\left[F_{3,92}=1.25, P=0.30\right]$ and growth $\left[F_{3,92}=0.47, P=0.71\right]$, Fig. 2a, b). Conversely, Vaccinium myrtillus had high survival rates under deep snow cover, and it showed severe dieback on blown-off ridges $\left(F_{3,92}=21.96, P<0.0001\right.$, Fig. 2a). The three other deciduous species exhibited intermediate responses with relatively high survival under deep snow cover and somewhat lower survival with increasing exposure. The shoot growth patterns of A. alpina and $V$. myrtillus resembled their shoot survival patterns, albeit no significant differences occurred between topography levels. The shoot growth of $V$. uliginosum was comparable to A. alpina and the growth of $V$. myrtillus tended to show vulnerability to changing environment (Fig. 2b). In terms of relative cover change after four years of the experiment, $S$. herbacea and $V$. myrtillus showed the greatest decrease on exposed ridges $(S$. herbacea $F_{3,28}=4.53, P<0.05$ and $V$. myrtillus $F_{3,28}=8.22$, $P<0.001$, Fig. 2c). Eventually, among evergreens, $P$. caerulea (Table 2) decreased at all levels of snow cover, whereas the cover of the three other evergreens appeared more stable over the time of the experiment (Fig. 2c).

\section{Shrub responses in relation to their initial traits}

Numerous significant relationships between initial aboveground architectural target traits and target performance responses were detected across and over the mesotopographic gradient (Appendices S1, S2, and S3). Initial shoot height appeared as an indicator of tundra shrub responses to snow-related gradient. At the functional type level, tallness appeared to be disadvantageous for the survival of deciduous species (Fig. 3a; Appendix S1: Tables S1 and S2), in particular on the blown-off ridges (height $\times$ topography interaction, Appendix S1: Table S1). Conversely, shoot height, as the based-on volume proxy (Fig. 3b), showed positive relationships with deciduous shoot growth and cover change indicating that taller and larger individuals grew more under thin and moderate snow cover, respectively (Appendix S1: Tables S1 and S2). At the species-specific level, tallness negatively affected survival of not only the deciduous $V$. myrtillus (Fig. 4a; Appendix S2: Tables S1 and S2) and V. uliginosum (Appendix S2: Table S2) but also the evergreen representative of the genus, $V$. vitis-idaea (Appendix S3: Table S2). However, these negative tallness-survival relationships were only detected under intermediate levels of snow cover. Interestingly, the survival rates of evergreens $P$. caerulea and $L$. procumbens were negatively and positively associated with their shoot height under deep and moderate snow cover, respectively (Appendix S3: Table S2).

Specific growth responses highlighted interesting architecture-dependent relationships across PFTs. The deciduous A. alpina and the evergreen E. nigrum shared a positive tallness-shoot-growth relationship while the deciduous $V$. myrtillus and the evergreen $P$. caerulea showed a negative largeness-shoot-growth relationship (Appendix S2: Table S2, Appendix S3: Table S2). The positive tallness-shoot-growth relationship significantly occurred regardless of snow cover level, under deep and thin snow cover for A. alpina and even on the blown-off ridges for E. nigrum. Eventually, considering changes in cover as a longer-term growth indicator, deciduous $V$. uliginosum showed a positive tallness-growth relationship under thin snow cover, while on the blown-off ridges, this same species showed a negative correlation between volume and change in cover (Appendix S2: Table S2).

TABLE 2. Effects of species identity within each plant functional type (PFT), topography and their interaction on target individual (a) survival and (b) growth after one year of the experiment, and (c) on target species change in cover after four years of the experiment tested by generalized linear models.

\begin{tabular}{|c|c|c|c|c|c|c|c|c|c|}
\hline \multirow[b]{2}{*}{ Source of deviation } & \multicolumn{3}{|c|}{ (a) Survival after 1 year } & \multicolumn{3}{|c|}{ (b) Growth after 1 year } & \multicolumn{3}{|c|}{$\begin{array}{l}\text { (c) Cover change } \\
\text { after } 4 \text { years }\end{array}$} \\
\hline & df & $F$ & $P$ & $\mathrm{df}$ & $F$ & $P$ & $\mathrm{df}$ & $F$ & $P$ \\
\hline \multicolumn{10}{|l|}{ Deciduous species } \\
\hline Species & 4 & 1.42 & 0.2259 & 4 & 6.51 & $<0.0001$ & 4 & 1.55 & 0.1902 \\
\hline Topography & 3 & 1.3 & 0.2737 & 3 & 0.64 & 0.5899 & 3 & 1.55 & 0.1797 \\
\hline Species $\times$ Topography & 12 & 4.09 & $<0.0001$ & 12 & 6.52 & $<0.0001$ & 12 & 1.65 & 0.0052 \\
\hline Residuals & 460 & & & 377 & & & 136 & 2.51 & \\
\hline \multicolumn{10}{|l|}{ Evergreen species } \\
\hline Species & 3 & 1.38 & 0.2486 & 3 & 1.51 & 0.2114 & 3 & 2.81 & 0.0429 \\
\hline Topography & 3 & 2.24 & 0.0831 & 3 & 1.68 & 0.1709 & 3 & 1.35 & 0.2632 \\
\hline Species $\times$ Topography & 9 & 1.05 & 0.3966 & 9 & 1.22 & 0.2846 & 9 & 0.56 & 0.8288 \\
\hline Residuals & 368 & & & 283 & & & 108 & & \\
\hline
\end{tabular}

Note: Boldface type indicates significant effects $(P<0.05)$ of the explanatory variables. 

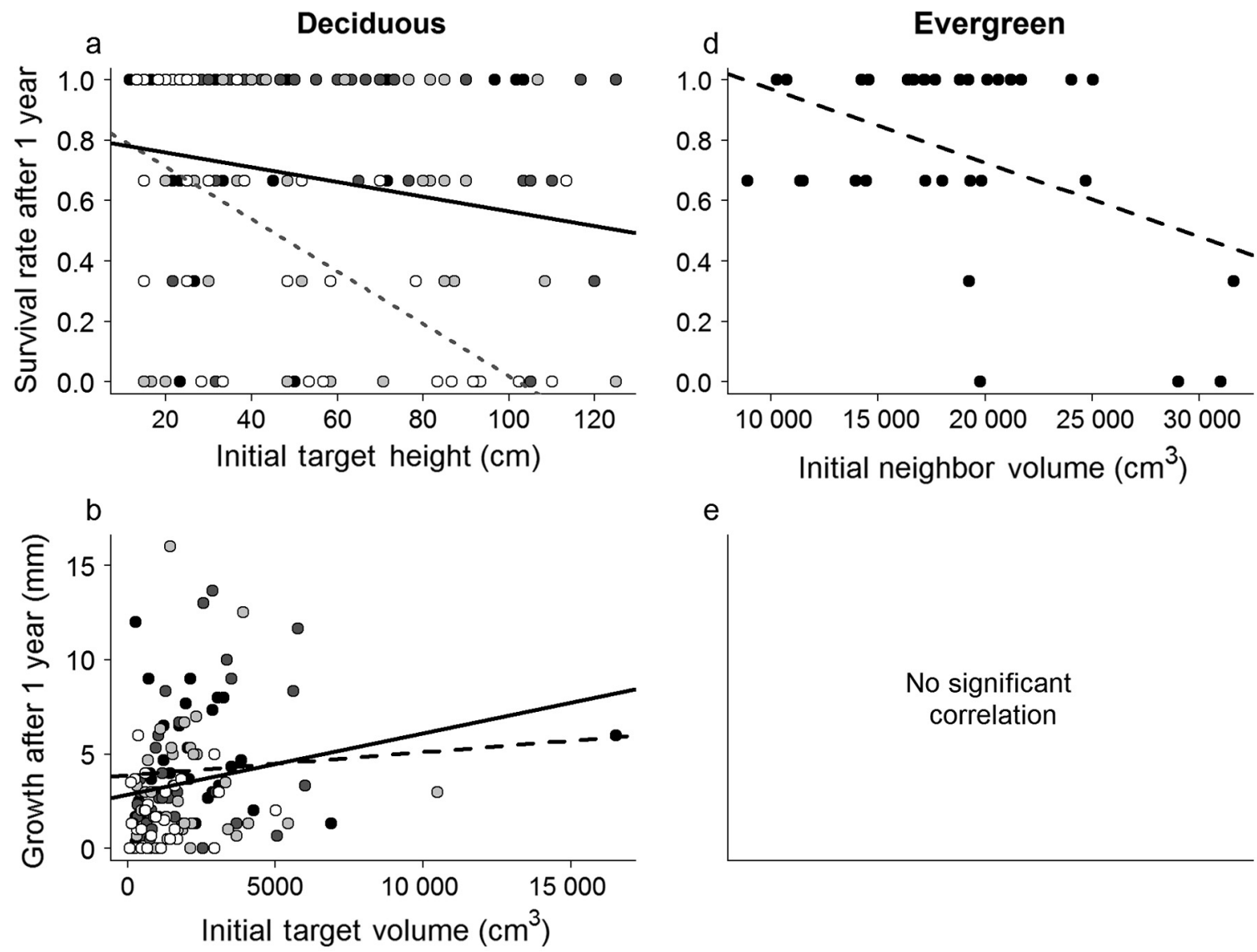

e

No significant correlation
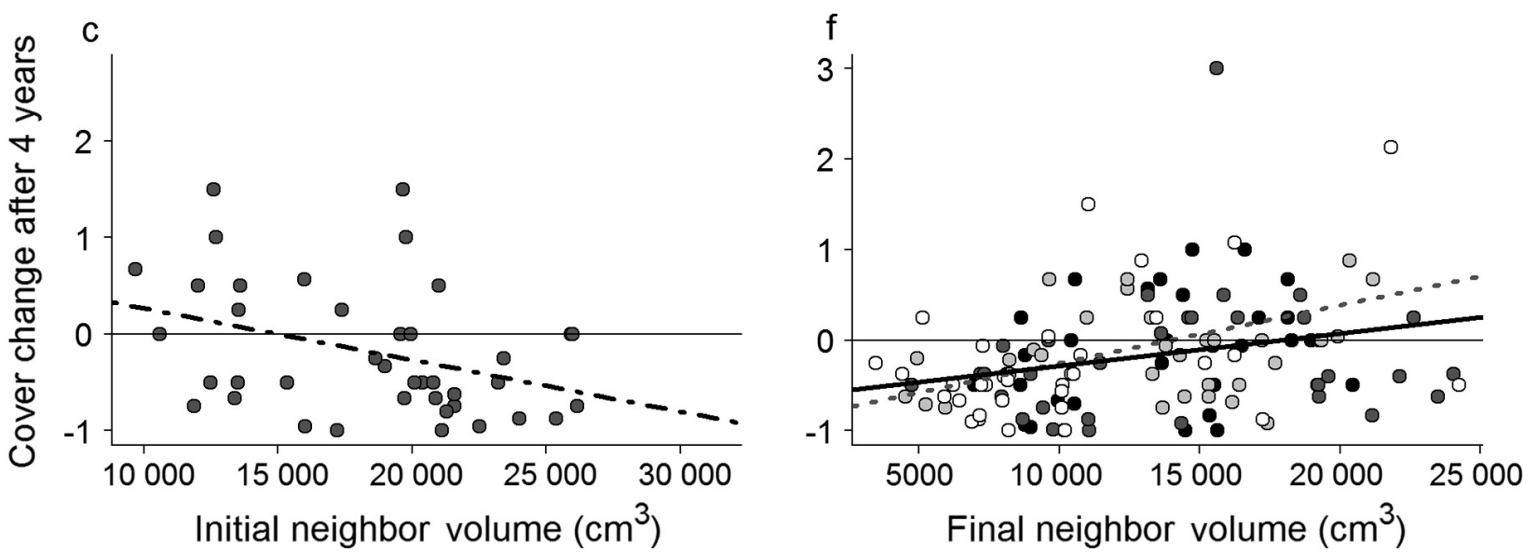

_- Deep ․․ - Moderate $\quad$ - 으-Thin …-Blown-off snow cover — Whole gradient

FIG. 3. Selected significant correlations between performance responses (a and d, survival; $b$ and e, growth; $c$ and $f$, change in cover) of deciduous and evergreen functional types and either target or neighborhood traits. Points from the four gradient levels were plotted when the correlation was found significant at the gradient scale, otherwise only significant levels were plotted. A complete summary of significant correlations is presented in the Appendix S1: Table S1.

\section{Shrub responses in relation to abundance of neighboring shrubs}

The abundance of neighboring shrubs also significantly modulated the target responses to snow-related gradient. At the PFT level, the neighbor volume limited the shoot growth and expansion of deciduous species at an intermediate level of exposure (Fig. 3c; Appendix S1: Table S2) and the survival of evergreen shrubs under the deep snow cover (Fig. 3d; Appendix S1: Tables S1 and S2). At the species level, competition was more specifically evidenced for the survival of the evergreen $P$. caerulea regardless of snow cover level (Appendix S3: Table S2), for $B$. nana survival in the snowbed 
Deciduous

a) Vaccinium myrtillus

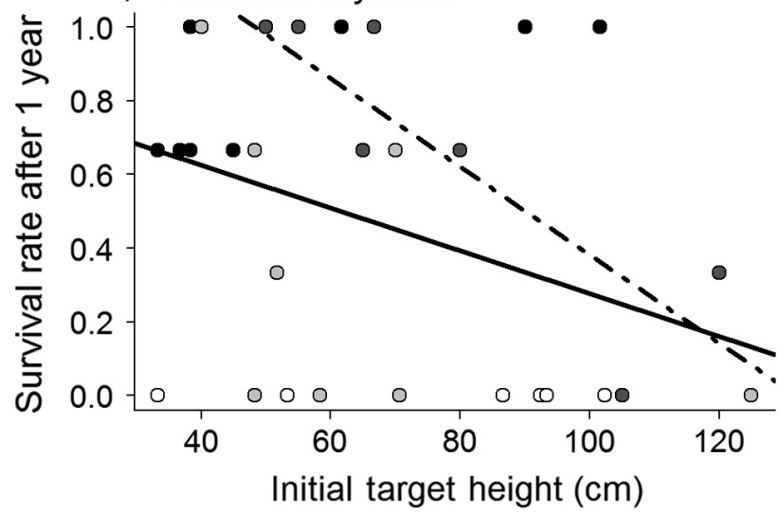

b) Betula nana

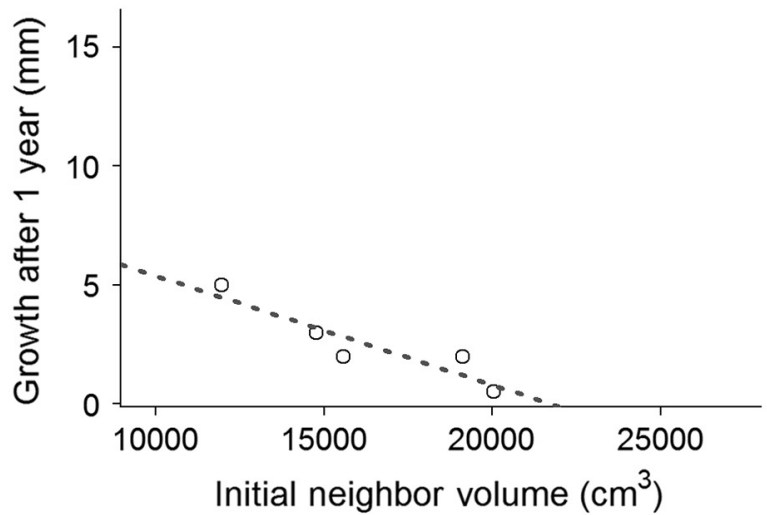

c) Arctostaphylos alpina

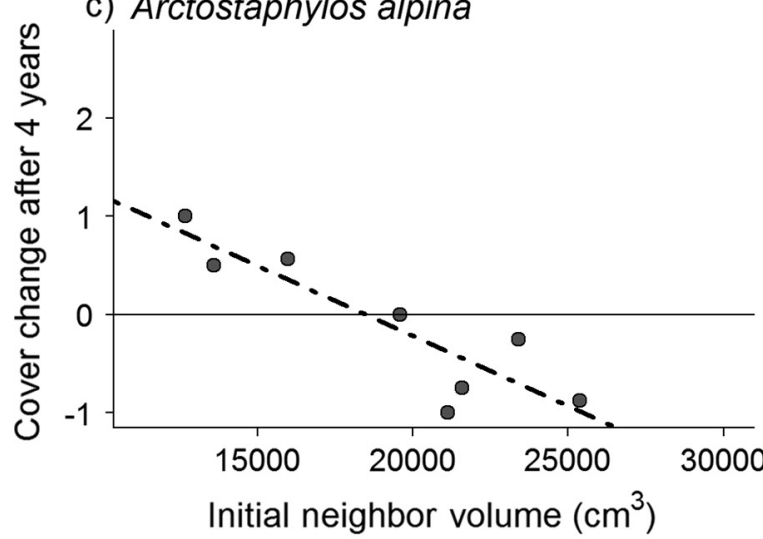

Evergreen

d) Loiseleuria procumbens

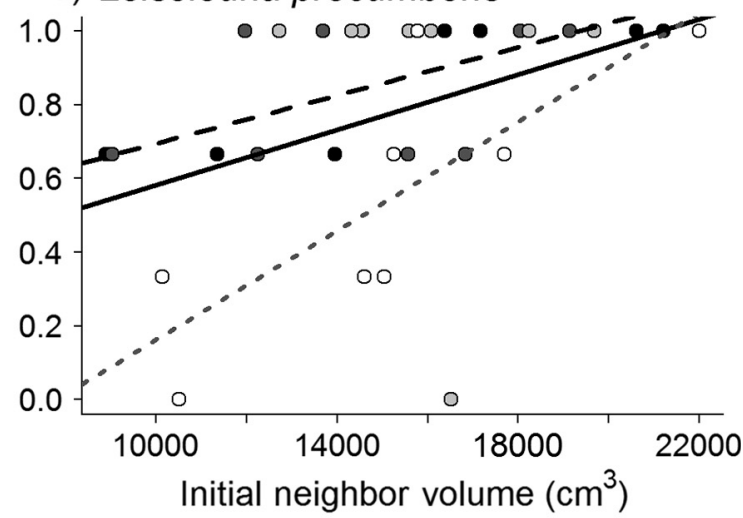

e) Phyllodoce caerulea
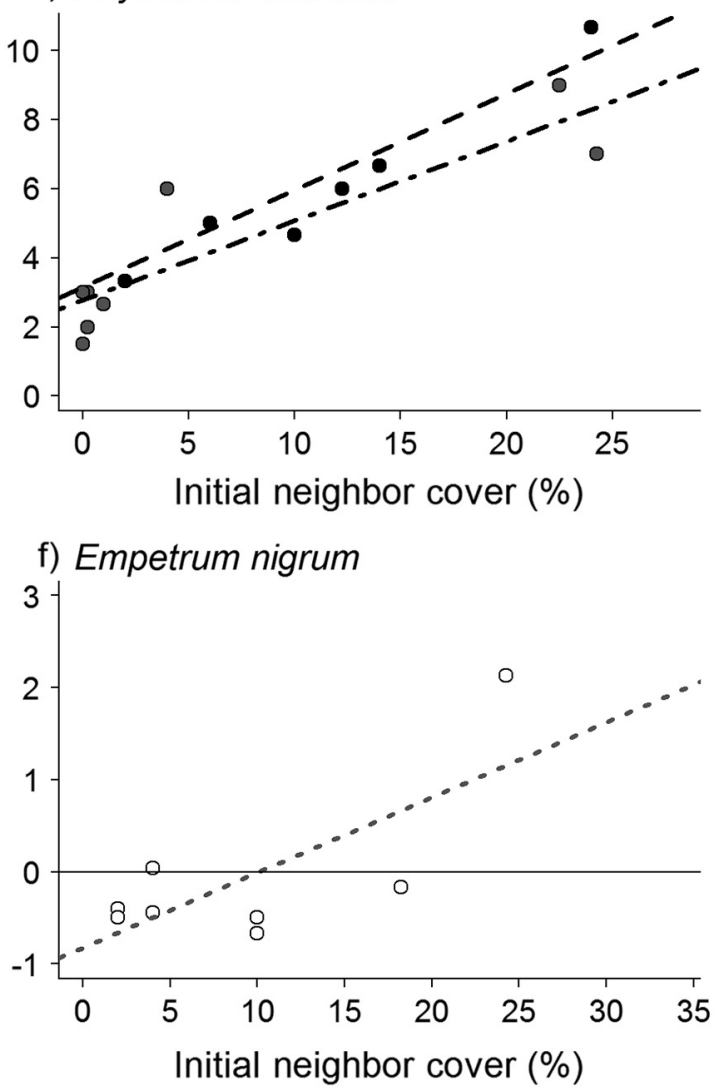

$\therefore$ Blown-off snow cover -Whole gradient

FIG. 4. Selected significant correlations between performance responses ( $a$ and $d$, survival; $b$ and e, growth; $c$ and $f$, change in cover) of deciduous and evergreen species and either target or neighborhood traits. Points from the four gradient levels were plotted when the correlation was found significant at the gradient scale, otherwise only significant levels were plotted. A complete summary of significant correlations is presented in the Appendix S2: Table S2 (for deciduous species) and Appendix S3: Table S2 (for evergreens species).

(Appendix S2: Tables S1 and S2) and shoot growth on the ridges (Fig. 4b), as well as for the change in cover over the four years of the experiment for A. alpina (Fig. 4c; Appendix S2: Tables S1 and S2) and $S$. herbacea
(Appendix S2: Table S2) under moderate snow cover. On the other hand, the survival of $L$. procumbens benefited from a shrubby neighborhood under both deep and blown-off snow cover (Appendix S3: Table S2). 
Interestingly, the intensity of the positive the relationships increased with environmental severity (Fig. 4d). The evergreens $P$. caerulea and $E$. nigrum also benefited from a shrubby neighborhood for their shoot growth and cover gain under the deepest and thinnest snow cover, respectively (Fig. 4e, f; Appendix S3: Table S2). Among deciduous species, direct evidence of facilitation was found for the shoot growth of $V$. myrtillus and cover gain of $B$. nana under moderate and thin snow cover, respectively (Appendix S2: Table S2). Eventually, the cover gain of evergreen species was also positively associated with final abundance of neighboring shrubs, indicating at least weak competitive interactions, in particular on the ridges at the PFT level (Fig. 3f) and specifically for E. nigrum, P. caerulea, and V. vitis-idea (Appendix S3: Table S2).

\section{Discussion}

The experimental transplantation of dwarf shrubs across a subarctic tundra mesotopographic gradient had significant effects on the survival and growth of most of the nine target species. Unexpectedly, we did not find either clear divergent response patterns between PFTs or any support to the hypothesis that deciduous shrubs would survive better than evergreen shrubs on the exposed blown-off ridges. On the other hand, evergreen species showed generally weaker responses to environmental constraints, whereas deciduous species showed stronger, yet remarkably contrasted responses. A negative relationship between initial shoot height and survival of deciduous shrubs under the thinnest snow conditions was observed. Nevertheless, links between architectural traits and target performances were very species specific. The responses of shrubs also depended on the abundance of neighboring shrubs. However, positive and negative effects were detected in both sheltered depressions and exposed ridges. These effects varied depending on functional type, species and metrics, highlighting the complex nature of plant-plant interactions and environmental conditions.

\section{Are leaf lifespan strategies key drivers of shrub distribution in the heterogeneous topography of subarctic tundra?}

Our results reveal deciduous and evergreen species can show similar responses to snow cover gradient, and subsequently, they do not provide support for a hypothesis of clear segregation based on leaf lifespan strategy. Therefore, also the hypotheses summarized by Givnish (2002:729) on adaptation benefits of leaf-shedding strategy to avoid dieback in snow-free tundra conditions are not supported. Instead, our results highlight prominent species-specific responses matching earlier studies showing strongly species-specific responses of tundra plants to environmental manipulations (Chapin and Shaver 1985, Press et al. 1998). Overall, there seem to be general limitations of the PFT approach for the generalization of plant response to environmental change (Dormann and Woodin 2002). Obviously, mesotopography generated a complex gradient including changes in many environmental factors such as wind abrasion, nutrient availability, growing season length, winter microclimate, or soil moisture (Billings 1973, Sonesson and Callaghan 1991, Walker 2001). Observed prominence of speciesspecific over PFT responses could illustrate how such multiple environmental constraints could drive both adaptation and selection at the species level.

Worldwide, the segregation of woody plants into evergreen and deciduous PFTs refers to the trade-off between acquisition and conservation of resources. The photosynthetic $\mathrm{N}$-use efficiency was consensually shown to be negatively correlated to leaf lifespan (Reich et al. 1992, Wright et al. 2005). In tundra habitats, evergreenness is commonly associated with dry and nutrient-deficient conditions, while the high leaf turnover of deciduous species can be advantageous when nutrients are available (Chapin et al. 1996) and under harsh winter conditions (Oksanen and Virtanen 1995, Virtanen et al. 1999, Givnish 2002). Here, our results suggest that regardless of a species' belonging to a PFT, they can share similar responses to environments. Indeed, the deciduous $A$. alpina exhibited similar resistance to changing environmental conditions as the evergreen species, and its natural high abundance on the ridges in the study area further confirmed the ecological relevance of the pattern. Moreover, the multivariate analysis by Odland and Munkejord (2008) also demonstrated the strictly chionophobous classification of this species. Along the same line, the three tested Vaccinium species (i.e., the deciduous $V$. myrtillus and $V$. uliginosum and the evergreen $V$. vitis-idaea) shared a common negative correlation between their performances and their height regardless of their PFT. These results support the idea that ecological strategies of plants are not necessarily linked to specific PFTs and that a single PFT can exhibit a wide range of plant strategic syndromes (Verheijen et al. 2016).

\section{Species' traits as predictors of shrub responses}

Billings (1973) characterized the tundra vegetation by its low stature where the production of vertical stems to elevate leaves above surrounding becomes a luxury in overall unproductive habitat and even can be risky with regard to the hazards of severe winter conditions above the snowpack. Warren Wilson (1959) described possible mechanisms of survival risks including mechanical injuries and drying. Accordingly, we found that shoot height could be an indicator of plant performance with overall negative relationships between tallness and survival in particular for deciduous species. Walker et al. (2001) detailed several mechanisms by which the decoupling between phyllosphere and rhizophere environments, respectively, above and below the snowpack injures tundra plant species. For instance, wind desiccation 
enhances evaporation, while frozen soil limits water uptake leading to an internal water deficit. Similarly, light and high surface temperature can promote photosynthesis while nutrient uptake is severely restricted. The negative relationships between $V$. myrtillus and $V$. uliginosum survival and their height at the moderate level of snow cover might refer to such mechanisms at a place where transplanted individuals reached heights close to the estimated snow depth. This finding supports ideas of Billings (1973) of increased mortality risk of tall shoots protruding above snow surface. On the other hand, we also found positive correlations between tallness or largeness and shoot growth or cover gain including for deciduous and evergreen species and under the thinnest snow covers. This relationship may simply illustrates that the biggest individuals tend to grow more, but also might limit the indicative potential of tallness for tundra shrubs' distribution. Eventually, the results for $P$. caerulea strongly suggest that tallness can be also disadvantageous for survival under deep snow cover. This finding might be connected to the species-specific physical constraints of deep snowpack (Sonesson and Callaghan 1991) making taller individuals more sensitive to stem injuries. We therefore contend that shrub architectural plant traits can be good indicators of their possible response to the environment, however, the architecture-plant response relationships can also be highly species and context-dependent making any generalization difficult.

\section{Plant interactions as modulating topographic effects}

The importance of plant interactions for community structuring in severe habitats has been frequently recognized and has been largely tested in the Arctic in the last decades (Callaway 2007). Both competitive and facilitative interactions have been detected (see, for instance, Dormann and Brooker 2002, Wipf et al. 2006) and are suspected to affect species distributions (Mod et al. 2016). Here, along a deep environmental gradient within the tundra we hypothesized that the SGH (Bertness and Callaway 1994) predicting a shift from competition to facilitation with environmental severity could be applied from the snowbeds to the ridges. Our results described diverse patterns among species, PFTs and metrics and some of them provided support for the SGH. First, the stress-tolerant L. procumbens (Walker et al. 2001) exhibited a surprisingly positive response to neighboring shrubs for survival both under deep snow cover and on the ridges, but the response was stronger in the latter case suggesting increasing facilitation with environmental severity. Second, at the PFT level evergreen survival was reduced by the initial neighboring shrubs in the snowbed, indicating competition. Moreover, their abundance shifted from retreat to expansion with increasing final neighbor volume on the ridges. Such a pattern does not indicate proper facilitative process, since both target and neighbor individuals can benefit from the same enhancement of environmental conditions. Even so, this result should indicate a decreasing competitive effect, and because the transplantation to the exposed ridges likely did not enhance the environmental conditions for the sod-block plants, emergence of proper facilitation appeared likely. On the other hand, we also found evidence of competition on the exposed ridges and of facilitation under deep snow cover, in particular considering the shoot growth metric. In other words, no definitive pattern of plant interactions emerged. Mechanisms underlying plant facilitation can be related to the buffering of abiotic or biotic stress and disturbance (microclimate harshness and amplitude, grazing pressure, etc.) and/or to the enhancement of resource access and availability (litter production, symbiotic association, etc.) (see Callaway 2007). Competition between plants deals with light, space and soil resource access. Although there is evidence for both competition and facilitation, underlying mechanisms are strongly context and species dependent (see for instance Saccone et al. 2009). Moreover, in these very low-productivity environments, the detection of biotic interactions can require experimentation on decadal time scales (Saccone and Virtanen 2016). It is likely that, in such habitats, the effect of neighboring shrubs in terms of litter production (Buckeridge et al. 2010) and nutrient uptake (McKane et al. 2002, Vankoughnett and Grogan 2014) combined with thickness-related snowpack effects on soil microbial activities (Schimel et al. 2004, Jusselme et al. 2016), litter decomposition (Saccone et al. 2013), and nutrient release jointly modulate the structure of the tundra along the mesotopographic gradient in the long-term.

\section{Functional types, traits, and plant interactions as drivers of arctic-alpine shrubs}

The lack of major differences in the responses of deciduous and evergreen shrubs to transplantation suggest that mere environmental filtering brought about by lack of snow protection is not a sufficient driver of abundance relationships between deciduous and evergreen shrubs. Our results strongly suggest that traits and attributes of individual species, in addition to interaction mechanisms, are also involved. It is likely that deciduous shrubs with leaf economic traits adapted to permafrost tundra conditions out-perform evergreens. In permafrost tundra conditions, soil resources are available in a more pulsed manner favoring the rapid lifestyle of deciduous species, and this leaf phenology type is more competitive than that of evergreens. In alpine tundra with no permafrost, soil resources are more stable and these favor the resource-conservative tactics of evergreens. In continental tundra areas, deciduous shrubs usually react most strongly to environmental manipulations (nutrient addition, warming, snowpack manipulation; Chapin et al. 1995, Wahren et al. 2005, Walker et al. 2006). In Fennoscandian tundra representing both arctic and alpine features, competitive shrubs include both evergreen and 
deciduous species. However, our results here suggest that deciduous shrubs are generally more competitive under a broader range of environmental conditions.

Eventually, most of the modeling efforts in the last decades converge toward the prediction of an increase of deciduous shrub species due to lengthening of the growing season and enhancement of nutrient availability. However, our results suggest that change in snow depth could counterbalance the positive deciduous response during the growing season and compensate the evergreen competitive disadvantage. Further, the results add to emerging winter ecology studies agreeing that altered snow regime could represent one of the most serious threats to tundra ecosystems (Milner et al. 2016, Virtanen et al. 2016, Wheeler et al. 2016) and underline the difficulty to assess the outcome of the multiple aspects of environmental and climate change for plant communities. Furthermore, ongoing climate change at high latitudes may increase the frequency of extreme weather events causing winter-time snow melt, which, in turn, may also increase the risk of damage to tundra shrub heath vegetation. Consequently, exposure of evergreen shrubs to abnormal desiccative snow-free conditions may be seen as "arctic browning" (Phoenix and Bjerke 2016). The different aspects of snow-related gradient including direct positive (insulation) and negative (weight, darkness) effects on vegetation as well as indirect positive (biogeochemical cycle enhancement) and negative (growing season delay) effects likely lead to our contrasting results and make predictions about the finescale consequences of changing snow regime hard to provide. Although our results outline promising response patterns of tundra shrubs to gradual snow cover conditions, further experiments are needed to test how gradual differences in growing season length or soil nutrient and water contents affect shrub responses. Additionally, testing how these responses change in the long-term including removal of any suspicion of transplantation effects, are crucially needed to disentangle underlying mechanisms.

\section{Conclusions}

Our results provide new insights on potentials and limitations of the use of PFT for generalization of the response of the tundra dwarf shrub community to environmental change. They emphasize the greater tolerance of evergreen shrubs to changing conditions and the risk associated with tallness for deciduous species. However, they also reveal notable levels of species specificity and shared behavior over PFT that support ideas that species-level investigations can produce a better understanding of the determinants of PFT (see also Clark 2016). Eventually, they highlight the importance of community-structuring mechanisms for the plant response to environmental conditions and join the merging consensus advocating for better inclusion of local-scale processes in ecological modeling.

\section{ACKNOWLEDGMENTS}

This research was financially supported by the Academy of Finland (project \#259072). We thank Kilpisjärvi Biological Station for logistical support during the setup and maintenance of the experiment. We thank Aaron Bergdahl for checking the language. The authors declare no conflict of interest.

\section{Literature Cited}

Albert, C. H., W. Thuiller, N. G. Yoccoz, A. Soudant, F. Boucher, P. Saccone, and S. Lavorel. 2010. Intraspecific functional variability: extent, structure and sources of variation. Journal of Ecology 98:604-613.

Bertness, M. D., and R. M. Callaway. 1994. Positive interactions in communities. Trends in Ecology \& Evolution 9: 191-193.

Billings, W. D. 1973. Arctic and alpine vegetations: similarities, differences, and susceptibility to disturbance. BioScience 23:697-704.

Bokhorst, S. F., J. W. Bjerke, H. Tømmervik, T. V. Callaghan, and G. K. Phoenix. 2009. Winter warming events damage sub-Arctic vegetation: consistent evidence from an experimental manipulation and a natural event. Journal of Ecology 97:1408-1415.

Braun-Blanquet, J. 1923. Über die Genesis der Alpenflora. Verhandlungen der naturforschenden Gesellschaft in Basel 35:243-261.

Brooker, R. W., and T. V. Callaghan. 1998. The balance between positive and negative plant interactions and its relationship to environmental gradients: a model. Oikos 81:196-207.

Bruno, J. F., J. J. Stachowicz, and M. D. Bertness. 2003. Inclusion of facilitation into ecological theory. Trends in Ecology \& Evolution 18:119-125.

Buckeridge, K. M., E. Zufelt, H. Chu, and P. Grogan. 2010. Soil nitrogen cycles rates in low arctic shrub tundra are enhanced by litter feedback. Plant and Soil 330:407-421.

Buitenwerf, R., and S. I. Higgins. 2016. Convergence among global biogeographical realms in the physiological niche of evergreen and deciduous vegetation. Global Ecology and Biogeography 25:704-715.

Callaway, R. M. 2007. Positive interactions and interdependence in plant communities. Springer, Dordrecht, Netherlands.

Carlsson, B. A., and T. V. Callaghan. 1991. Positive plant interactions in tundra vegetation and the importance of shelter. Journal of Ecology 79:973-983.

Chabot, B. F., and D. J. Hicks. 1982. The ecology of leaf life spans. Annual Review of Ecological Systematics 13:229259.

Chapin, F. S. III, M. S. Bret-Harte, S. E. Hobbie, and H. Zhong. 1996. Plant functional types as predictors of transient responses of arctic vegetation to global change. Journal of Vegetation Science 7:347-358.

Chapin, F. S. III, and G. R. Shaver. 1985. Individualistic growth response of tundra plant species to environmental manipulations in the field. Ecology 66:564-576.

Chapin, F. S., G. R. Shaver, A. E. Giblin, K. J. Nadelhoffer, and J. A. Laundre. 1995. Responses of arctic tundra to experimental and observed changes in climate. Ecology 76:694-711.

Clark, J. S. 2016. Why species tell more about traits than traits about species: predictive analysis. Ecology 97:1979-1993.

Dahl, E. 1957. Mountain vegetation in South Norway and its relation to environment. Matematisk-Naturvidenskapelig klasse. Norske Videnskaps-Akademi, Oslo, Norway.

Díaz, S., and M. Cabido. 1997. Plant functional types and ecosystem function in relation to global change. Journal of Vegetation Science 8:463-474. 
Díaz, S., J. Kattge, J. H. Cornelissen, I. J. Wright, S. Lavorel, S. Dray, B. Reu, M. Kleyer, C. Wirth, and I. C. Prentice. 2016. The global spectrum of plant form and function. Nature 529:167-171.

Diaz, S., et al. 2004. The plant traits that drive ecosystems: evidence from three continents. Journal of Vegetation Science 15:295-304.

Dormann, C. F., and R. W. Brooker. 2002. Facilitation and competition in the high Arctic: the importance of experimental approach. Acta Oecologica 23:297-301.

Dormann, C., and S. Woodin. 2002. Climate change in the Arctic: using plant functional types in a meta-analysis of field experiments. Functional Ecology 16:4-17.

Engemann, K., B. Sandel, B. J. Enquist, P. M. Jørgensen, N. Kraft, A. Marcuse-Kubitza, B. McGill, N. MoruetaHolme, R. K. Peet, and C. Violle. 2016. Patterns and drivers of plant functional group dominance across the Western Hemisphere: a macroecological re-assessment based on a massive botanical dataset. Botanical Journal of the Linnean Society 180:141-160.

Epstein, H. E., F. S. Chapin Iii, M. D. Walker, and A. M. Starfield. 2001. Analyzing the functional type concept in arctic plants using a dynamic vegetation model. Oikos 95:239-252.

Fox, J., and S. Weisberg. 2011. An R companion to applied regression. Sage, Thousand Oaks, California, USA.

Giblin, A., K. Nadelhoffer, G. Shaver, J. Laundre, and A. McKerrow. 1991. Biogeochemical diversity along a riverside toposequence in arctic Alaska. Ecological Monographs 61:415-435.

Givnish, T. J. 2002. Adaptive significance of evergreen vs. deciduous leaves: solving the triple paradox. Silva Fennica 36:703-743.

Grime, J. P. 1977. Evidence for the existence of three primary strategies in plants and its relevance to ecological and evolutionary theory. American Naturalist 111:1169-1194.

Grubb, P. 2016. Trade-offs in interspecific comparisons in plant ecology and how plants overcome proposed constraints. Plant Ecology \& Diversity 9:3-33.

Guisan, A., and W. Thuiller. 2005. Predicting species distribution: offering more than simple habitat models. Ecology Letters 8:993-1009.

Heegaard, E. 2002. A model of alpine species distribution in relation to snowmelt time and altitude. Journal of Vegetation Science 13:493-504.

Heegaard, E., and V. Vandvik. 2004. Climate change affects the outcome of competitive interactions - an application of principal response curves. Oecologia 139:459-466.

Higgins, S. I., R. Buitenwerf, and G. Moncrieff. 2016. Defining functional biomes and monitoring their change globally. Global Change Biology 22:3583-3593.

Jusselme, M.-D., P. Saccone, L. Zinger, M. Faure, X. Le Roux, N. Guillaumaud, L. Bernard, J.-C. Clement, and F. Poly. 2016. Variations in snow depth modify N-related soil microbial abundances and functioning during winter in subalpine grassland. Soil Biology and Biochemistry 92:27-37.

Kattge, J., S. Diaz, S. Lavorel, I. Prentice, P. Leadley, G. Bönisch, E. Garnier, M. Westoby, P. B. Reich, and I. Wright. 2011. TRY - a global database of plant traits. Global Change Biology 17:2905-2935.

Kikuzawa, K. 1991. A cost-benefit analysis of leaf habit and leaf longevity of trees and their geographical pattern. American Naturalist 138:1250-1263.

Kunstler, G., D. Falster, D. A. Coomes, F. Hui, R. M. Kooyman, D. C. Laughlin, L. Poorter, M. Vanderwel, G. Vieilledent, and S. J. Wright. 2016. Plant functional traits have globally consistent effects on competition. Nature 529:204-207.
Lavorel, S., S. Díaz, J. H. C. Cornelissen, E. Garnier, S. P. Harrison, S. McIntyre, J. G. Pausas, N. Pérez-Harguindeguy, C. Roumet, and C. Urcelay. 2007. Plant functional types: are we getting any closer to the Holy Grail? Pages 149-164 in J. G. Canadell and L. F. Pitelka, editors. Terrestrial ecosystems in a changing world. Springer, Berlin, Germany.

Manzoni, S., G. Vico, S. Thompson, F. Beyer, and M. Weih. 2015. Contrasting leaf phenological strategies optimize carbon gain under droughts of different duration. Advances in Water Resources 84:37-51.

McKane, R. B., L. C. Johnson, G. R. Shaver, K. J. Nadelhoffer, E. B. Rastetter, B. Fry, A. E. Giblin, K. Kielland, B. L. Kwiatkowski, and J. A. Laundre. 2002. Resource-based niches provide a basis for plant species diversity and dominance in arctic tundra. Nature 415:68-71.

de Mendiburu, F. 2014. agricolae: statistical procedures for agricultural research. R package version 1.09. http://CRAN. R-project.org/package $=$ agricolae

Milner, J. M., Ø. Varpe, R. Wal, and B. B. Hansen. 2016. Experimental icing affects growth, mortality, and flowering in a high Arctic dwarf shrub. Ecology and Evolution. doi:10. 1002/ece3.2023.

Mod, H. K., R. K. Heikkinen, P. C. le Roux, H. Väre, and M. Luoto. 2016. Contrasting effects of biotic interactions on richness and distribution of vascular plants, bryophytes and lichens in an arctic-alpine landscape. Polar Biology 39: 649-657.

Mod, H. K., P. C. le Roux, A. Guisan, and M. Luoto. 2015. Biotic interactions boost spatial models of species richness. Ecography 38:913-921.

Odland, A., and H. K. Munkejord. 2008. Plants as indicators of snow layer duration in southern Norwegian mountains. Ecological Indicators 8:57-68.

Oksanen, L., and R. Virtanen. 1995. Topographic, altitudinal and regional patterns in continental and suboceanic heath vegetation of northern Fennoscandia. Acta Botanica Fennica 153:1-80.

Phoenix, G. K., and J. W. Bjerke. 2016. Arctic browning: extreme events and trends reversing arctic greening. Global Change Biology. doi:10.1111/gcb.13261.

Preece, C., T. V. Callaghan, and G. K. Phoenix. 2012. Impacts of winter icing events on the growth, phenology and physiology of sub-arctic dwarf shrubs. Physiologia Plantarum 146:460-472.

Press, M., J. Potter, M. Burke, T. Callaghan, and J. Lee. 1998. Responses of a subarctic dwarf shrub heath community to simulated environmental change. Journal of Ecology 86:315327.

R Development Core Team. 2013. R: A language and environment for statistical computing. R Foundation for Statistical Computing, Vienna, Austria. www.r-project.org

Reich, P. B., M. B. Walters, and D. S. Ellsworth. 1992. Leaf lifespan in relation to leaf, plant, and stand characteristics among diverse ecosystems. Ecological Monographs 62:365392.

Saccone, P., S. Delzon, J.-P. Pagès, J.-J. Brun, and R. Michalet. 2009. The role of biotic interactions in altering tree seedling responses to an extreme climatic event. Journal of Vegetation Science 20:403-414.

Saccone, P., and R. Virtanen. 2016. Extrapolating multi-decadal plant community changes based on medium-term experiments can be risky: evidence from high-latitude tundra. Oikos $125: 76-85$

Saccone, P., et al. 2013. The effects of snowpack properties and plant strategies on litter decomposition during winter in subalpine meadows. Plant and Soil 363:215-229. 
Scheiter, S., L. Langan, and S. I. Higgins. 2013. Next-generation dynamic global vegetation models: learning from community ecology. New Phytologist 198:957-969.

Schimel, J. P., C. Bilbrough, and J. M. Welker. 2004. Increased snow depth affects microbial activity and nitrogen mineralization in two Arctic tundra communities. Soil Biology and Biochemistry 36:217-227.

Shipley, B. 2010. From plant traits to vegetation structure: chance and selection in the assembly of ecological communities. Cambridge University Press, Cambridge.

Silvertown, J. 2004. Plant coexistence and the niche. Trends in Ecology \& Evolution 19:605-611.

Sonesson, M., and T. V. Callaghan. 1991. Strategies of survival in plants of Fennoscandian tundra. Arctic 44:95-105.

Stanton, M. L., M. Rejmanek, and C. Galen. 1994. Changes in vegetation and soil fertility along a predictable snowmelt gradient in the Mosquito Range, Colorado, USA. Arctic and Alpine Research 26:364-374.

Vankoughnett, M. R., and P. Grogan. 2014. Nitrogen isotope tracer acquisition in low and tall birch tundra plant communities: a 2 year test of the snow-shrub hypothesis. Biogeochemistry 118:291-306.

Vankoughnett, M. R., and P. Grogan. 2016. Plant production and nitrogen accumulation above-and belowground in low and tall birch tundra communities: the influence of snow and litter. Plant and Soil. doi:10.1007/s11104-016-2921-2.

Verheijen, L. M., R. Aerts, G. Bönisch, J. Kattge, and P. M. Van Bodegom. 2016. Variation in trait trade-offs allows differentiation among predefined plant functional types: implications for predictive ecology. New Phytologist 209:563-575.

Vestergren, T. 1902. Om den olikformiga snöbetäckningens Inflytande på vegetationen i Sarjekfällen. Botaniska Notiser 1902:241-268.

Virtanen, R., L. Oksanen, T. Oksanen, J. Cohen, B. C. Forbes, B. Johansen, J. Käyhkö, J. Olofsson, J. Pulliainen, and H. Tømmervik. 2016. Where do the treeless tundra areas of northern highlands fit in the global biome system: toward an ecologically natural subdivision of the tundra biome. Ecology \& Evolution 6:143-158.

von Humboldt, A. 1806. Ideen zu einer Physiognomik der Gewächse. J. G. Cottaschen Buchhandlung, Tübingen.
Virtanen, R., L. Oksanen, and V. Razzhivin. 1999. Topographic and regional patterns of tundra heath vegetation from northern Fennoscandia to the Taimyr Peninsula. Acta Botanica Fennica 167:29-83.

Wahren, C. H. A., M. D. Walker, and M. S. Bret-Harte. 2005. Vegetation responses in Alaskan arctic tundra after 8 years of a summer warming and winter snow manipulation experiment. Global Change Biology 11:537-552.

Walker, D. A., W. D. Billings, and J. G. De Molenaar. 2001. Snow-vegetation interactions in tundra environments. Pages 266-324 in H. G. Jones, J. W. Pomeroy, D. A. Walker, and R. W. Hoham, editors. Snow ecology. Cambridge University Press, Cambridge, UK.

Walker, M. D., et al. 2006. Plant community responses to experimental warming across the tundra biome. Proceedings of the National Academy of Science 103:1342-1346.

Warren Wilson, J. 1959. Notes on wind and its effects in arcticalpine vegetation. Journal of Ecology 47:415-427.

Westoby, M., and I. J. Wright. 2006. Land-plant ecology on the basis of functional traits. Trends in Ecology \& Evolution 21:261-268.

Wheeler, J. A., A. J. Cortés, J. Sedlacek, S. Karrenberg, M. Kleunen, S. Wipf, G. Hoch, O. Bossdorf, and C. Rixen. 2016. The snow and the willows: earlier spring snowmelt reduces performance in the low-lying alpine shrub Salix herbacea. Journal of Ecology. doi:10.1111/1365-2745. 12579.

Wijk, S. 1986. Performance of Salix herbacea in an alpine snowbed gradient. Journal of Ecology 74:675-684.

Wipf, S., C. Rixen, and C. P. H. Mulder. 2006. Advanced snowmelt causes shift towards positive neighbour interactions in a subarctic tundra community. Global Change Biology $12: 1-11$.

Wright, I. J., et al. 2005. Assessing the generality of global leaf trait relationships. New Phytologist 166:485-496.

Wullschleger, S. D., H. E. Epstein, E. O. Box, E. S. Euskirchen, S. Goswami, C. M. Iversen, J. Kattge, R. J. Norby, P. M. van Bodegom, and X. Xu. 2014. Plant functional types in Earth system models: past experiences and future directions for application of dynamic vegetation models in high-latitude ecosystems. Annals of Botany 114:1-16.

\section{SUPPORTING INFORMATION}

Additional supporting information may be found in the online version of this article at http://onlinelibrary.wiley.com/doi/ 10.1002/ecy.1817/suppinfo 